\title{
Representações Sociais do Trabalho Artesanal: Estudo de Caso de uma Associação de Artesãos em Viçosa, Minas Gerais - Brasil
}

\author{
Social Representations of the Artisan Work: Study of Case of an Association of Craftsmen \\ in Viçosa, Minas Gerais - Brazil
}

\author{
Alair Ferreira de Freitas* \\ Alan Ferreira de Freitas ${ }^{* *}$
}

\begin{abstract}
Resumo:
Este artigo objetiva analisar as Representações Sociais do trabalho artesanal para os artesãos associados à Associação dos Artesãos e Produtores de Alimentos Caseiros de Viçosa, Minas Gerais - Brasil (Adapac). Com este fim, procurou-se identificar e analisar a trajetória destes e os motivos que os levaram a se envolver com o artesanato, bem como as representações do trabalho artesanal para artesãos vinculados a esta associação. A estratégia metodológica adotada para a pesquisa consistiu no estudo de caso. Como instrumento de coleta de dados, foram utilizadas a observação participante e a aplicação de entrevistas semiestruturadas. O método da "análise de conteúdo" foi utilizado na organização e análise dos dados. Para discussão dos resultados foram definidas duas categorias analíticas: (i) motivações para o trabalho artesanal e (ii) representações do trabalho artesanal. Os resultados mostram que este tipo de trabalho é associado como principal oportunidade de ocupação e geração de renda encontrada por alguns associados e outra como vocação e habilidades manuais. Para as mulheres, as representações sociais do trabalho artesanal relacionam-se a condição de satisfação pessoal e possibilidade de conciliação com as atividades domésticas, enquanto que, para os homens, as representações indicam a valorização da dimensão econômica do trabalho artesanal, distinguindo-o das atividades domésticas.
\end{abstract}

Palavras-chave: Representações Sociais. Associação. Trabalho.

\begin{abstract}
:
This article aims to analyze the social representations of small-scale artisans working for associated Association of Artisans and food producers Homemade of Viçosa, Minas Gerais State-Brazil (Adapac). To this end we have tried to identify and analyse the trajectory of the craftsmen and the reasons for becoming involved with crafts and renditions of the craft for craftsmen linked to this Association. The methodological strategy adopted for the research consisted in case study. As an instrument of data collection, were used to survey participant and application of
\end{abstract}

\footnotetext{
* Mestre em Extensão Rural e Bacharel em Gestão de Cooperativas. Assessor da Secretaria de Estado de Desenvolvimento Econômico de Minas Gerais. alairufv@yahoo.com.br.

** Mestre em Extensão Rural e Bacharel em Gestão de Cooperativas. Professor Assistente da Universidade Federal de Uberlândia. freitasalan@yahoo.com.br.
} 
semi-structured interviews. The method of "content analysis" was used in the Organization and analysis of data. For discussion of the results were defined two categories: (i) motivations for the craft and (ii) representations of the craft. The results show that this type of work associates itself as the premier opportunity to occupation and income generation found by some members and another as vocation and manual skills. For women the social representations of craft relate the condition of personal satisfaction and possibility of reconciliation with the domestic activities, while for men representations indicate the enhancement of the economic dimension of the craft, distinguishing it from domestic activities.

Keywords: Social representations. Association. Work.

\section{Introdução}

Nos últimos anos, o conceito de Representação Social, originário das obras do psicólogo social Serge Moscovici, vem ganhando grande destaque na literatura científica, principalmente sobre os domínios das ciências humanas. Contudo, é um conceito de dimensão irrestrita aos limites de uma única disciplina. Ele é transversal às propostas analíticas que envolvam o entendimento do comportamento humano e sua constituição como constructo social. O objetivo da teoria das representações sociais é explicar os fenômenos sociais a partir de uma perspectiva coletiva, porém, sem negar a individualidade (MOSCOVICl, 2003).

Trata-se de um conceito, como veremos, (re)construído pela Psicologia Social de Moscovici. Entretanto, foi Durkheim quem primeiro teorizou sobre o fenômeno, mas com perspectivas distintas das atribuídas por Moscovici décadas depois. Moscovici retoma ao conceito de Representações Coletivas de Durkheim, mas provoca mudanças significativas em seu conteúdo, dotando-o de novas capacidades explicativas acerca dos fenômenos sociais contemporâneos (OLIVEIRA, 2004).

Nesta direção, a Representação Social é compreendida como importante base teórica para analisar a construção social do conhecimento e as interações sociais (MOSCOVICl, 1988). O uso deste conceito como categoria analítica possibilita entender relações estabelecidas por indivíduos e (dentro dos) grupos, bem como as mudanças e permanências promovidas socialmente. As Representações Sociais nos guiam no modo de "nomear e definir conjuntamente diferentes aspectos da realidade diária, no modo de interpretar esses aspectos, tomar decisões e, eventualmente, posicionar-se frente a eles de forma defensiva" (JODELET, 2002, p. 17). 
Partimos, aqui, da premissa de que as Representações Sociais são fenômenos complexos, sempre ativados e em ação na vida social, dando um sentido de verdade e uma eficácia simbólica a determinadas práticas e ações, como, por exemplo, o trabalho humano em suas diferentes formas.

Neste artigo, o objetivo é analisar as Representações Sociais do trabalho artesanal para os artesãos $^{1}$ associados à Associação dos Artesãos e Produtores de Alimentos Caseiros de Viçosa, Minas Gerais - Brasil (Adapac). Para isso, procurou-se identificar e analisar a sua trajetória e os motivos que os levaram a se envolver com o artesanato, e as representações sobre o trabalho artesanal para os artesãos vinculados à Adapac que participam de uma feira semanal de artesanato na zona urbana da cidade de Viçosa, organizada por esta associação. Este recorte analítico se justifica por permitir compreender, a partir das trajetórias e condições sociais, como se estruturam as representações sobre uma "forma de trabalho autônoma, sem subordinação direta, mas também sem estabilidade" (artesã entrevistada). O recorte se mostrou privilegiado porque permitiu redimensionar a posição do trabalho artesanal na vida dos artesãos a partir de uma distinção das representações por uma questão de gênero.

Ao se propor estudar as Representações Sociais de um determinado grupo, há que se considerar o contexto em que estas representações se manifestam e também seu potencial na transformação deste contexto. Por isso, as análises desenvolvidas a seguir tentam delimitar o contexto de operacionalização do trabalho enquanto prática a ser representada e as interferências de sua representação sobre as configurações do trabalho no cotidiano dos indivíduos e grupos sociais.

\section{Referencial Teórico: Representações Sociais}

O conceito de Representações Sociais (RS) possui profundas raízes na sociologia, e uma presença marcante na antropologia e na história das mentalidades (ARRUDA, 2002). Como supracitado, este conceito é concebido por Moscovici sob referenciais da Psicologia Social, por meio de sua apropriação e abstração do conceito de Representações Coletivas

\footnotetext{
${ }^{1}$ Onde se lê artesãos, leia-se artesãos e artesãs. Esta expressão esta sendo usada apenas para facilitar a leitura.
} 
de Durkheim, da orientação teórica do construtivismo de Piaget e dos estudos sobre o inconsciente de Freud.

Foi Durkheim o primeiro a identificar objetos e práticas como produções mentais sociais, extraídos de seus estudos sobre ideação coletiva (DURKHEIM, 1978), dos quais ele formula o conceito de Representações Coletivas. Contudo, como argumenta Arruda (2002), este conceito consistia em um grande guarda-chuva que abrigava crenças, mitos, imagens, e também o idioma, o direito, a religião, as tradições. Tal abrangência tornava, porém, o conceito pouco operacional e não dava conta de compreender concretamente o conteúdo da realidade.

Não obstante a tese durkheimiana sobre as representações coletivas estar correta, o problema encontrava-se nos detalhes, nas singularidades, ou seja, no fato de que as representações coletivas tratam de fenômenos gerais e os relacionam as práticas ou realidades que não o são (OLIVEIRA, 2004). Por tais motivos Moscovici procede à remodelagem do conceito durkheimiano, buscando assim preencher essa lacuna a partir da teorização sobre as Representações Sociais e não mais "coletivas", como em Durkheim. Moscovici dirige-se, portanto, ao conceito de representações coletivas de Durkheim para iniciar o percurso de sua teorização sobre as Representações Sociais. Assim, provoca uma renovação das categorias analíticas, insistindo sobre a especificidade dos fenômenos representativos nas sociedades contemporâneas, caracterizadas por: intensidade e fluidez das trocas e comunicações; desenvolvimento da ciência; pluralidade e mobilidade sociais (JODELET, 2002).

Ao retomar o conceito de Durkheim, Moscovici não o utilizou apenas numa perspectiva crítica, mas sim e, sobretudo, com a intenção construtiva de fornecer à Psicologia Social instrumentos conceituais e metodológicos que permitissem um conhecimento concreto e cumulativo, em contato direto com as verdadeiras questões colocadas pela vida social. De acordo com Moscovici (2003), a psicologia social absorve o conceito de Representações Sociais, concebendo-o como fenômeno que possui mobilidade e circularidade.

O conceito de Representações Sociais formulado por Moscovici é inicialmente operacionalizado para trabalhar com o pensamento social em sua dinâmica e em sua diversidade, partindo da premissa de que existem formas diferentes de conhecer e de se 
comunicar, guiadas por objetivos diferentes; formas que são móveis. Duas dessas formas são definidas como: a consensual e a científica, cada uma gerando seu próprio universo (ARRUDA, 2002; JODELET, 2002). A diferença não significa hierarquia nem isolamento entre elas, apenas propósitos diversos. O universo consensual se trata do espaço da vida cotidiana, onde se constitui uma racionalidade comunicativa, enquanto o universo reificado se cristaliza no espaço científico, com seus cânones de linguagem e sua hierarquia interna. Ambas, portanto, "apesar de terem propósitos diferentes, são eficazes e indispensáveis para a vida humana. As representações sociais formam-se mais freqüentemente na esfera consensual, embora as duas esferas não sejam totalmente estanques" (ARRUDA, 2002, p. 129).

Os processos de formação das representações explicam sua estruturação. Essa formação é constituída basicamente pelos processos de objetivação e ancoragem. Esta classificação sobre os processos da formação das Representações Sociais é concebida na perspectiva de Moscovici e reforçada principalmente por Jodelet (2002), uma de suas principais colaboradoras e atual expoente sobre o tema.

O processo de objetivação é decomposto em três fases: construção seletiva, esquematização estruturante e naturalização. Esse processo busca esclarecer como se estrutura o conhecimento do objeto. Inicialmente, acontece a seleção e descontextualização de elementos daquilo que será representado, operando-se assim um enxugamento do excesso de informação. Esta sofre cortes baseados na informação prévia, na experiência e nos valores internalizados. Uma vez feitos os recortes, reestruturam-se os fragmentos num esquema que se torna o núcleo figurativo da representação. Desta forma, o que era misterioso foi devidamente destrinchado, recomposto, e se torna algo objetivo (ARRUDA, 2002).

Conteúdos e estruturas são infletidos por outro processo, a ancoragem, que intervém ao longo do processo de formação das representações, assegurando sua incorporação ao social. De acordo com Jodelet (2002, p. 38), por um lado, "a ancoragem enraíza a representação e seu objetivo numa rede de significações que permite situá-lo em relação aos valores sociais e dar-Ihes coerência". Por outro lado, "a ancoragem serve para a instrumentalização do saber, conferindo-lhe um valor funcional para a interpretação e a gestão do ambiente". Para Arruda (2002), a ancoragem busca trazer a 
novidade ao território conhecido da nossa bagagem nocional, ancorar aí o novo, o desconhecido, retirando-o da sua navegação às cegas pelas águas do não familiar.

Neste sentido, as Representações Sociais são abordadas concomitantemente como produto e processo de uma atividade de apropriação da realidade exterior ao pensamento e de elaboração psicológica e social dessa realidade (JODELET, 2002). Uma vez consideradas como produtos sociais, as Representações Sociais devem ser relacionadas às condições sociais sob as quais emergiram e ao contexto social em que estão imersas.

Uma das definições mais consensuais sobre o conceito de Representações Sociais no meio acadêmico entre os pesquisadores da área é a de Denise Jodelet. Para esta autora, as Representações Sociais são "uma forma de conhecimento, socialmente elaborada e partilhada, com um objetivo prático, e que contribui para a construção de uma realidade comum a um conjunto social" (JODELET, 2002, p. 22).

A autora sugere que, para abarcar o conjunto de componentes e relações contidos na Representação Social, vista como saber prático, é preciso responder a três perguntas fundamentais: Quem sabe, e a partir de onde sabe? O que e como se sabe? Sobre o que se sabe, e com que efeito? Estas perguntas revelam três planos que compõe a dimensão analítica do conceito, que ela sistematizou como: 1) as condições de produção e de circulação das Representações Sociais; 2) os processos e estados; e 3) o estatuto epistemológico das Representações Sociais (JODELET, 2002). Para Jodelet, tais problemáticas são interdependentes e abrangem os temas dos trabalhos teóricos e empíricos que cercam o campo das Representações Sociais.

Jodelet (2002) destaca também que as Representações Sociais são, por um lado, sistemas que registram nossa relação com o mundo e com os outros, orientando e organizando as condutas e as comunicações sociais. Por outro, interferem nos processos, diversificando a difusão e assimilação dos conhecimentos, o desenvolvimento individual e coletivo, a definição das identidades pessoais e sociais, a expressão dos grupos e transformações sociais.

Neste sentido, Spink (apud HOROCHOVSKI, 2004) argumenta que as representações possuem duas faces, a de estruturas estruturadas e estruturas estruturantes, pois se inscrevem num contexto sócio-histórico-cultural determinado ao mesmo tempo em que 
expressam uma realidade "intraindividual". Isto evidencia um duplo movimento em que as representações sociais se inserem: influenciam a construção da realidade social ao mesmo tempo em que são por ela influenciadas.

É em meio a esse duplo movimento que as Representações Sociais operam uma transformação do sujeito e do objeto. Isso na medida em que ambos são modificados no processo de elaboração simbólica do objeto na dimensão cognitiva do sujeito.

\begin{abstract}
O sujeito amplia sua categorização e o objeto se acomoda ao repertório do sujeito, repertório o qual, por sua vez, também se modifica ao receber mais um habitante. A representação, portanto, repito, não é cópia da realidade, nem uma instância intermediária que transporta o objeto para perto/dentro do nosso espaço cognitivo. Ela é um processo que torna conceito e percepção intercambiáveis, uma vez que se engendram mutuamente, como no caso do inconsciente ou do complexo visível a olho nu (ARRUDA, 2002, p. 137).
\end{abstract}

Não se trata de uma cópia nem um reflexo, uma imagem fotográfica da realidade; as Representações Sociais são uma tradução, uma versão desta. "A estrutura imagética da representação se torna guia de leitura e, por generalização funcional, teoria de referência para compreender a realidade" (JODELET, 2002, p. 39). É sob esta perspectiva que as Representações Sociais se tornam referência para o estudo do comportamento humano e da vida social de forma geral. Os pressupostos acima referidos formam o referencial teórico que ampara a análise do material empírico dessa pesquisa, apresentada nos itens a seguir.

\title{
Metodologia
}

A estratégia metodológica da pesquisa orientou-se pela realização de um estudo de caso da Adapac. Trata-se, como observou Trivinõs (1987), de um estudo de caso de natureza qualitativa, pois além de permitir uma reflexão aprofundada sobre as estruturas sociais do fenômeno em particular, permite também a identificação de outros fenômenos ligados à história de vida dos sujeitos. Como instrumento de coleta de dados, foi utilizada a observação participante durante a feira de artesanato, que acontece aos sábados na Praça Silviano Brandão, centro da cidade de Viçosa, Minas Gerais. Utilizou-se também de entrevistas semiestruturadas dirigidas aos artesãos associados à Adapac. A entrevista 
semiestruturada ao mesmo tempo em que valoriza a presença do investigador, oferece todas as perspectivas possíveis para que o informante alcance a liberdade e a espontaneidade necessárias, enriquecendo a investigação (TRIVIÑOS, 1987). A coleta de dados foi realizada no mês de novembro de 2009 durante dois sábados, enquanto ocorria a feira de artesanato. Antes da coleta de dados propriamente dita, o roteiro de entrevista foi submetido a um pré-teste para garantir sua eficácia.

Os sujeitos desta pesquisa correspondem aos associados participantes da feira semanal de artesanato. Consideraram-se apenas aqueles que participavam da feira, devido ao fato de que a associação não tem um espaço físico próprio e a dispersão de seus membros é grande, sendo a feira o momento principal de integração dos artesãos. Durante a pesquisa de campo, constatou-se que a população da pesquisa consistia em 15 artesãos cujas barracas estavam expostas na feira e expunham regularmente. A amostra colhida corresponde a oito (8) artesãos, sendo seis (6) mulheres e dois (2) homens. Como a feira acontece apenas na parte da manhã e o fluxo de pessoas nas barracas nos dias da entrevista era grande, os informantes foram escolhidos aleatoriamente, sendo que a amostra foi definida segundo a proporção entre homens e mulheres que estavam expondo seus produtos e a disponibilidade para a realização das entrevistas. Apesar de não ser uma amostra de determinação probabilística, como ela compreendeu mais de 50\% da população, pode-se considerá-la significativa e representativa da população (GIL, 2002).

Para a organização e análise dos dados, utilizou-se o método "análise de conteúdo" (BARDIN, 2009). Este método foi utilizado como uma ferramenta para a compreensão da construção de significados que os atores sociais exteriorizam no discurso. A análise de conteúdo, como argumentam Laville e Dionne (1999), não segue etapas rígidas e predeterminadas, mas uma reconstrução simultânea de um conteúdo com as percepções do pesquisador com vias possíveis e nem sempre balizadas. Sob esta perspectiva, estes autores assinalam que "a análise de conteúdo consiste em demonstrar a estrutura e os elementos desse conteúdo para esclarecer suas diferentes características e extrair sua significação" (LAVILLE; DIONNE, 1999, p. 214). 
A análise de conteúdo foi realizada por meio de três etapas, como sugerido por Laville e Dionne (1999), quais sejam: o recorte de conteúdos, a definição das categorias e a categorização final das unidades de análise.

O Recorte de Conteúdos, na qual os conteúdos coletados (os relatos) foram decompostos para em seguida serem reorganizados para melhor expressar sua significação, teve a finalidade de agrupar elementos em função de sua significação. Essa reorganização buscou recortar o conteúdo seguindo uma proximidade de sentido, contendo fragmentos do discurso e ideias temáticas. Os elementos recortados constituíram as unidades de análise, chamadas também de unidades de classificação ou registro. Na Definição das categorias analíticas, após reorganizados os dados sob os devidos recortes, foram estabelecidas as categorias analíticas que orientaram as análises. As categorias analíticas, de acordo com Laville e Dionne (1999), são "rubricas sob as quais virão se organizar os elementos do conteúdo agrupados por parentesco de sentido". A definição das categorias analíticas e suas subcategorias seguiu o "modelo misto"2 (LAVILLE; DIONNE, 1999), no qual elas são selecionadas no início, mas foram modificadas e complementadas em função do que a análise aportou. As características de cada categoria (apresentadas no item seguinte) foram cuidadosamente revisadas após a categorização para precisar suas distinções. As características foram resumidas em um título, baseado nas estruturas sintáticas dos conteúdos, especificamente as estruturas gramaticais, como frases e orações, as quais permitiram expor mais facilmente o sentido das categorias e, principalmente, de suas derivações em subcategorias. As categorias analisadas neste trabalho foram agrupadas seguindo a frequência de aparecimento de certos termos e orações, similares aos apresentados no título atribuído. A categorização final das unidades de análise tratou-se de uma análise de verificação e reconsideração da alocação dos conteúdos sob determinados recortes e sua categorização, a fim de otimizar e qualificar a organização e análise dos dados.

Neste trabalho foram analisadas duas principais categorias. A primeira era direcionada pelos conteúdos ligados aos motivos que levaram os entrevistados ao

\footnotetext{
${ }^{2}$ Além do modelo misto, outros dois modelos são sugeridos por Laville e Dionne (1999), quais sejam: (i) o modelo aberto, em que as categorias não são fixadas no início, mas tomam forma no decorrer das análises; e (ii) o modelo fechado, em que as categorias são determinadas antes da própria análise, apoiando-se em um ponto de vista teórico, e não se alteram ao longo da pesquisa.
} 
trabalho artesanal; e a segunda aos conteúdos que expunham os sentidos sobre as representações sociais do trabalho artesanal. O Quadro 1, exposto abaixo, apresenta as categorias analíticas formuladas e subcategorias derivadas delas, definidas por parentesco de sentido, bem como o número de entrevistados que o compõem. Vale ressaltar que foram oito entrevistados e todos estão relacionados em cada uma das categorias, divididos em cada subcategoria para explicitar seu enquadramento nestas.

Quadro 1 - Categorias analíticas

\begin{tabular}{|c|c|c|}
\hline \multirow{2}{*}{ Categoria analítica } & Subcategoria & Número de entrevistados \\
\hline \multirow{2}{*}{$\begin{array}{c}\text { Motivos que levaram } \\
\text { ao trabalho artesanal }\end{array}$} & $\begin{array}{c}\text { "A melhor oportunidade de } \\
\text { ocupação e geração de renda } \\
\text { encontrada" }\end{array}$ & 5 mulheres e 1 homem \\
\cline { 2 - 4 } & "Vocação e habilidades manuais" & 1 mulher e 1 homem \\
\hline \multirow{2}{*}{$\begin{array}{c}\text { Representações sobre } \\
\text { o trabalho artesanal }\end{array}$} & "Caminho para ganhar dinheiro" & 6 mulheres \\
\cline { 2 - 4 } & "Satisfação pessoal" & 2 homens \\
\hline
\end{tabular}

Fonte: Dados da pesquisa.

\section{ADAPAC: Trajetória e Contexto}

A Adapac surgiu por iniciativa de um grupo de artesãos frente à necessidade de valorização e comercialização de seus produtos, composto por cinco pessoas do município de Viçosa, no estado de Minas Gerais, Brasil. Estes cinco artesãos se conheciam, e alguns deles ligados a entidades da Igreja Católica. Pela estreita relação com entidades religiosas locais, mediados por um padre e então pároco da comunidade a que pertenciam (Paróquia de Santa Rita), eles foram convidados a participar de uma feira realizada pela Igreja. Foi a partir desta feira que os artesãos perceberam a necessidade de organizar o grupo e agregar mais artesãos.

Por consequência desta experiência, os artesãos solicitaram ao padre um local para a exposição de seus produtos. Foi-lhes concedido um espaço numa praça pública, localizada em frente à Igreja Matriz. Após algum tempo de exposição em conjunto dos cinco artesãos, eles foram a Leopoldina/MG participar de uma feira regional de artesanato. Nesta feira participaram diversos artesãos de diversas regiões do estado. Um 
dos encaminhamentos dessa feira foi a necessidade do associativismo entre os artesãos. A proposta final era constituir uma associação regional de artesanato. Contudo, após retornarem à Viçosa, o grupo avaliou ser inviável uma associação regional, pois os custos de reunião e logística seriam altos. Ademais, o próprio município de Viçosa, seguindo a avaliação, apresentava grande potencial para constituir uma associação própria.

A localização geográfica do município de Viçosa, onde o caso aqui analisado se manifesta, pode ser visualizada na Figura 1:

Figura 1 - Localização do município de Viçosa

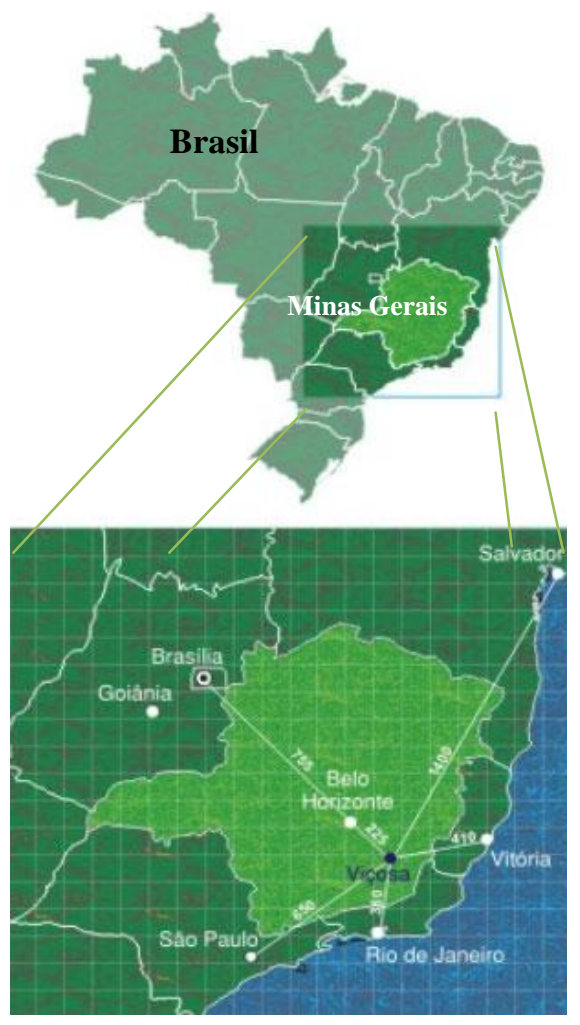

Fonte: Extraído de www.vicosa.mg.gov.br

Para não perder o entusiasmo, o grupo começou a mobilizar mais artesãos para a posterior constituição de uma associação municipal. Em fevereiro de 1993, um grupo formado por seis artesãos constituiu a primeira associação dos artesãos do município de Viçosa, denominada de Associação dos Artesãos e Produtores de Alimentos caseiros de Viçosa/MG (Adapac). Os seis artesãos passaram a se reunir periodicamente e a exporem também seus produtos semanalmente na praça em frente à igreja matriz, no centro da cidade. Essa exposição semanal, também denominada de feira de artesanato de Viçosa, 
tornou-se o principal ponto de vendas para os artesãos e referência do segmento na cidade.

Após três anos de fundação, a Associação conseguiu agregar ao todo 45 associados. Entretanto, como relatado nas entrevistas, após cerca de quatro anos funcionando com esse número de associados, a Adapac passou por uma grave crise financeira, ocasionada pela dificuldade nas vendas do artesanato. Nesse período, o número de associados foi reduzido drasticamente, chegando a 11 artesãos. Estes artesãos que resistiram à crise nas vendas (principalmente por que o artesanato não representava para eles a única fonte de renda) permaneceram por cerca de 10 anos, momento em que começam a aparecer novos artesãos interessados a comporem o quadro social da Adapac.

Em novembro de 2009, a Adapac contava novamente com o expressivo número de 45 artesãos associados. Dentre estes, a maioria era de mulheres, sendo apenas cinco homens registrados como associados. ${ }^{3}$ Contudo, é válido ressaltar que apesar de não estarem registrados, outros homens participavam regularmente das atividades da associação e do artesanato, acompanhando suas esposas e familiares. A composição etária da associação é muito variada, desde jovens de 19 anos até idosos de 70 anos. Porém, a maioria dos associados e dos expositores da feira semanal é de adultos entre 27 e 45 anos.

Qualquer artesão de Viçosa pode se tornar associado na Adapac, desde que não venda produtos industrializados ou importados. A Adapac só permite trabalhar com a linha dos produtos artesanais. Além disto, para ser efetivado como associado é preciso contribuir com uma taxa de filiação no valor de $\mathrm{R} \$ 20,00$ e a contribuição mensal de $\mathrm{R} \$$ 10,00, correspondente à manutenção da associação e à montagem e desmontagem das barracas na feira semanal.

Esta feira é a principal atividade organizada pela associação, é o principal ponto de encontro entre os artesãos e destes com os consumidores. Todos os associados devem participar da feira, mas sendo registrada a ausência de algum associado por três meses

\footnotetext{
${ }^{3}$ Ressalta-se que essa divisão diz respeito ao nome do associado registrado. Portanto, a presença de homens e mulheres na feira não reproduz essa questão, uma vez que os cônjuges, filhos e parentes também contribuem com este trabalho.
} 
consecutivos ele perde o direito de uso de seu lugar específico na feira. ${ }^{4}$ A feira conta com o apoio da Igreja Matriz da Paróquia de Santa Rita e da Prefeitura Municipal de Viçosa.

Atualmente, a Adapac é registrada como uma ONG (Organização Não Governamental) e, por isso, conseguiram o certificado de organização civil de utilidade pública. Segundo um dos informantes, ex-presidente da Adapac, enquanto ONG com certificado de utilidade pública, o grupo tem direito a receber certo montante de recurso público por parte do governo federal, o qual é destinado a financiar a participação dos artesãos em feiras regionais.

\section{Resultados e Discussões: As Representações Sociais do Trabalho Artesanal}

Os Motivos que Levaram ao Trabalho Artesanal

Esta seção pretende analisar as trajetórias de vida dos entrevistados, focando nos caminhos percorridos até o encontro com o trabalho artesanal. Isso se torna importante tendo em vista que as Representações Sociais devem ser relacionadas às condições sociais sob as quais emergiram e ao contexto social em que estão imersas. Assim, o objetivo proposto é identificar os motivos que levaram os entrevistados a trabalharem com o artesanato. Para tanto, iremos expor a seguir duas categorias, referentes aos motivos identificados nas trajetórias dos associados entrevistados.

"A melhor oportunidade de ocupação e geração de renda encontrada"

Este subtítulo é uma frase registrada durante a pesquisa de campo e sintetiza um dos principais motivos de contato com o trabalho artesanal, por isso sua inserção como categoria de análise. Aqui se identificam seis dos oito entrevistados, sendo cinco mulheres e um homem. Em síntese, este grupo ingressou no trabalho artesanal a partir de momentos de crise na vida financeira da família ("aperto", como foi mencionado pelo

\footnotetext{
${ }^{4}$ De acordo com a presidente da associação, mesmo que o artesão esteja pagando em dia sua mensalidade, se for contabilizada sua falta por três meses consecutivos na feira, ele perderá o lugar específico de exposição de sua barraca e ficará sujeito aos lugares desocupados, geralmente em pontos de menor circulação de pessoas.
} 
homem), desencadeados principalmente por falta de oportunidades no mercado formal de trabalho local.

Três das cinco mulheres afirmaram ter procurado no artesanato uma estratégia de geração de renda devido à má situação financeira dos maridos, aos quais é atribuído o papel de "responsáveis pelas despesas da casa" (mulher entrevistada). A fala de uma das entrevistadas sintetiza o motivo que levou este grupo ao trabalho artesanal: "foi por causa da situação financeira do marido, para ajudar em casa também". Assim, para fins de complementar a renda do marido, conjugando uma ocupação familiar (classificada como "trabalho doméstico") a uma atividade econômica que pode ser desenvolvida na unidade doméstica, as mulheres admitem o trabalho artesanal como estratégia de reprodução social de suas famílias, conciliando os "afazeres de casa" com uma "forma de gerar renda". O trabalho "junto com a família" foi apontado pelas mulheres como um dos principais fatores de continuação no trabalho artesanal, pois este não as priva do trabalho doméstico.

O trabalho artesanal, concebido como um trabalho inserido e realizado na esfera doméstica é representado como um trabalho doméstico. O trabalho doméstico, por envolver o espaço da família como o lugar da ação, como a manifestação do cuidado, é associado à figura da mãe, que zela pelo lar. É acessório à atividade econômica principal, desenvolvida externamente pelo homem.

Desta forma, o trabalho artesanal e o trabalho doméstico, sendo atividades análogas para o grupo estudado, são representados como ocupações basicamente femininas. Isto auxilia a compreensão da permanente predominância de mulheres associadas à Adapac.

De acordo com Jodelet (2002), as representações expressam aqueles (indivíduos ou grupos) que as forjam. No caso acima, as representações são forjadas por um grupo com dificuldades econômicas históricas, expressas principalmente pelo insucesso no mercado formal de trabalho. Por isso, as representações dão uma definição específica ao objeto representado (trabalho artesanal). Essas definições, ou representações metais partilhadas pelo grupo constroem uma visão "consensual" do trabalho artesanal. Esse tipo de representação partilhada "[...] é uma guia para as ações e trocas cotidianas - trata-se das funções e da dinâmica social das representações" (JODELET, 2002, p. 22). 
Cabe ressaltar que apenas uma mulher relatou já ter tido experiência no mercado de trabalho formal. O motivo pelo qual ingressou no trabalho artesanal foi convergente com as demais, ou seja, a busca por um trabalho que the garantisse mais dignidade e possibilidade de melhor renda. No entanto, frente à sua particular experiência de trabalho formal, caracterizado como "obediência e subordinação", esta mulher foi buscar no trabalho artesanal a "autonomia e a independência" que lhe foi retirada no trabalho anterior: "ser patrão de você mesmo faz toda a diferença" (entrevistada). Portanto, agregam-se outras variáveis além da busca por renda. Essa entrevistada alia a qualidade nas relações de trabalho e sua autonomia à busca pela oportunidade de geração de renda.

Por sua trajetória de vida diferenciada, apesar de o motivo de ingresso no trabalho artesanal ser o mesmo dos entrevistados já analisados, a representação sobre esse trabalho é diferente. Como discutido por Jodelet (2002), o contexto pelo qual a representação é formada muda o seu conteúdo e atribui diferentes sentidos ao objeto representado.

Em relação ao homem desta categoria, este relatou ter começado a trabalhar com o artesanato quando foi obrigado a deixar o emprego por limitações físicas. ${ }^{5}$ Por isso conseguiu sua aposentadoria. Com a obrigatoriedade de pagar aluguel para manter a moradia, seus baixos rendimentos financeiros mensais se tornaram escassos, desembocando em dificuldades financeiras. Durante o período em que ele era empregado formal, sua esposa já trabalhava com artesanato para complementar a renda. Porém, o trabalho artesanal era concebido como atividade econômica secundária complemento à atividade principal desenvolvida pelo marido. Neste caso, diante do desemprego do homem e sua limitação física de conseguir outro emprego, ele passou a integrar o campo de trabalho da mulher, apropriando o trabalho artesanal como a melhor alternativa de renda, tendo em vista suas condições físicas e financeiras.

A inserção do homem em um trabalho representado como acessório e da mulher modifica a própria valoração atribuída ao trabalho. O trabalho artesanal passa a ser representado como "a saída", como um "trabalho importante, muito necessário para a

\footnotetext{
${ }^{5}$ Ele era caminhoneiro e perdeu parte das funções auditivas, ficando impossibilitado física e legalmente de continuar no emprego.
} 
nossa sobrevivência" (entrevistado). A visão sobre o objeto representado é alterada pela mudança dos atores que representam e da posição desses atores em relação ao objeto representado. A representação está em transformação como o objeto que tenta elaborar. É dinâmica, móvel, como definido por Arruda (2002).

\section{Vocação e habilidades manuais}

Nesta categoria encontram-se dois entrevistados (um homem e uma mulher), que iniciaram o trabalho artesanal por consequência de suas vocações e de serem dotados de habilidades manuais importantes para garantir a eficiência no trabalho e a qualidade do produto. Ambos expressaram que tais habilidades são heranças de família, tendo este argumento como justificativa a continuidade neste trabalho e a perpetuação das tradições dos antepassados.

Não obstante a vocação, ao relatarem a trajetória de vida, o trabalho artesanal só ganha destaque no discurso quando, em um determinado momento do relato, ele se associa à dimensão econômica como fonte de renda. No caso da mulher, apesar de já trabalhar com artesanato, "foi a partir de uma encomenda para elaborar bolsas artesanais para uma loja" (mulher entrevistada) que este trabalho ganhou expressividade em sua vida, projetando-se como ocupação e fonte de renda. No relato de sua trajetória, somente quando chega a esta etapa (da encomenda) é que o trabalho artesanal é citado. A partir de então o discurso começa a retroagir para contar as experiências anteriores. No caso do homem, foi a partir da criação de uma confecção artesanal por seus parentes que surgiu a demanda comercial para o artesanato e, assim, a motivação para o trabalho. Esse se tornou o ponto de referência em sua trajetória no que diz respeito ao trabalho artesanal.

Em ambos os casos o artesanato não é a única fonte de renda da família. A mulher conta com a renda do marido para a reprodução social da família. Por conseguir um retorno considerável com o artesanato, ela mantém duas "ajudantes" para bordar e costurar, "pois o filho é pequeno e o marido trabalha fora" (mulher entrevistada). 0 homem tem um trabalho formal ("de carteira assinada" como relatou) e "contribui mais é no processo de venda" (homem entrevistado). A produção é operada pela mãe: "ela é quem coordena o trabalho com artesanato na familia" (homem entrevistado). 
Percebe-se, então, que o trabalho artesanal é significado por valores diferentes dos relatados na categoria anterior. Apesar da similaridade como forma de complementar a renda, o trabalho artesanal é perpetuado no âmbito da família como vocação e herança. O trabalho artesanal, neste contexto de representação, não se trata de ser "a melhor oportunidade encontrada", mas sim e, sobretudo, de ser a operacionalização da tradição como estratégia de reprodução da família. Essas representações apoiam-se em valores variáveis - segundo os grupos sociais dos quais tiram suas significações - e em saberes anteriores, reavivados por uma situação social particular (JODELET, 2002), qual seja, a da necessidade de geração de renda.

\section{A Representação do Trabalho Artesanal}

Nesse bloco foram identificadas duas principais categorias analíticas: a primeira, que representa o trabalho artesanal como "satisfação pessoal"; e a segunda, como "caminho para ganhar dinheiro", esta última sempre enfatizando a dimensão econômica quase que como exclusiva função do trabalho. Estas duas categorias, como percebido durante a pesquisa de campo, dizem respeito a uma explícita distinção de gênero. $\mathrm{Na}$ primeira categoria se incluem todas as mulheres entrevistadas (6), e a segunda categoria é composta exclusivamente pelos homens entrevistados (2).

É válido ressaltar que todos os entrevistados relataram que o artesanato (produto) é uma importante fonte de renda ou uma complementação de renda necessária à reprodução da família. Não obstante esta evidência consensual, as Representações Sociais do trabalho artesanal (processo) não necessariamente seguirão uma correlação direta. Isso, que poderia ser um consenso entre o grupo, esbarra, para além do contexto, na diferenciação de gênero. Neste sentido, a categoria "caminho para ganhar dinheiro", foi assim denominada não pela função atribuída ao produto (artesanato), mas sim ao processo, às práticas que elaboram o produto - ao trabalho artesanal. Para desenvolvermos analiticamente as duas categorias citadas ("satisfação pessoal" e "caminho para ganhar dinheiro"), iremos discuti-las separadamente a seguir. 


\section{"Caminho para ganhar dinheiro"}

Os entrevistados desta categoria, ao se reportarem ao trabalho artesanal, o associam exclusivamente à sua dimensão econômica. Em síntese, o processo de trabalho é um meio para a geração de renda e este é também o seu fim.

Os principais termos (maior frequência de aparecimento no conteúdo analisado) relacionados à importância do trabalho artesanal para os homens entrevistados são: "fonte de renda", "complemento de renda" e "saída econômica". Estes termos encontram-se no centro da argumentação discursiva dos entrevistados ao se reportarem ao processo de trabalho artesanal. A postura masculina frente a este trabalho isola a dimensão econômica, que apesar de fundamental, não é única na composição deste trabalho como processo social, assim como veremos com as mulheres.

Essa percepção dos entrevistados congrega uma categoria de representações sobre o trabalho que valoriza expressamente a dimensão econômica como central no processo. A essa categoria denominamos de "caminho para a geração de renda", seguindo uma das falas de um entrevistado. Esta fala sintetiza a representação desse grupo, que projeta o trabalho artesanal como o caminho a ser seguido para alcançar melhor nível de renda, ou seja, o trabalho artesanal apenas como fonte de renda é um processo instrumental para a geração de um produto que precisa ser transformado em dinheiro. "O trabalho artesanal é difícil, mas gera renda porque o artesanato é bom de venda. Ele é um bom complemento pra a renda da família" (homem entrevistado).

Porém, o papel central dos homens no processo de trabalho, como relatado nas entrevistas, é acessório às mulheres, as quais assumem a coordenação do trabalho. Os homens são, nesses casos, encarregados da elaboração de poucas peças (panos de prato e caixas de presente são as mais comuns.), sob a supervisão da mulher. O papel principal dos homens é no processo de venda. Ambos os entrevistados ajudam as mulheres (um a esposa e o outro a mãe) na produção do artesanato, mas são encarregados principalmente da negociação para a venda.

Evidencia-se nesse caso a separação entre as esferas da produção e da comercialização. Tal distinção é nitidamente reforçada por uma questão de gênero. $\mathrm{Na}$ produção, as mulheres são quem assumem o processo de trabalho. Já na comercialização são os homens que coordenam o trabalho ligado à venda, pois é nesta etapa que se 
estabelece preço, uma relação econômica, limitando a relação de trabalho a uma definição mercantil sobre o valor do bem.

Esta associação dos homens à parte comercial do artesanato é um dos fatores do contexto que atuam na construção da representação do trabalho como "caminho para a geração de renda". A vinculação acessória desses homens à produção e a valorização da etapa comercial é condicionante e condicionada pelas Representações Sociais do trabalho artesanal.

No entanto, essa vinculação dos homens à etapa da comercialização não é espontânea. A representação do trabalho artesanal como um trabalho basicamente feminino é um fator preponderante para entender o papel dos homens nessa divisão sexual do trabalho. As mulheres se ocupam da produção do artesanato, de um trabalho ligado, sobretudo, às tarefas domésticas, pois são, nestes casos, realizadas no âmbito da unidade doméstica. Já os homens se apropriam principalmente das atividades externas, que não se encontram densamente misturadas à esfera doméstica. O trabalho de venda do artesanato, a coordenação das transações com os fregueses, é uma atividade representada como basicamente masculina, que envolve a condução de negociações, atributos que, para os homens entrevistados, dizem respeito às "qualidades masculinas". De acordo com a fala de um dos homens entrevistados, é possível compreender melhor esta análise: "O artesanato quem faz é minha esposa, ela é que tem mais habilidade $e$ começou primeiro nisso. E eu fico responsável por ajudar mais é na venda, aqui [na feira] precisa mais de mim pra ajudar a negociar os preços com o freguês" (homem entrevistado).

As representações sociais remetem-se, portanto, à maneira com que os homens pensam, agem e procuram compreender o sentido de suas ações e pensamentos (HOROCHOVSKI, 2004). Os sentidos do trabalho artesanal nessa categoria deságuam na distinção sexual do trabalho e na vinculação dos homens à etapa do trabalho executada "fora de casa", que envolve os domínios da ação masculina em um ambiente de transações e à dimensão econômica frente à Representação Social do trabalho artesanal como "caminho para a geração de renda". 


\section{"Satisfação pessoal"}

A composição desta categoria exclusivamente pelas mulheres entrevistadas foi feita pela grande aproximação das Representações Sociais do trabalho artesanal. Ao falarem sobre o processo de trabalho artesanal as mulheres o associaram, basicamente, a uma condição de "satisfação pessoal", expressão mencionada por duas mulheres entrevistadas, mas similar a outras expressões no conteúdo das falas das demais entrevistadas. O trabalho está ligado a uma ocupação prazerosa e estimulante na rotina, associado à sua função de geração de renda. Essa função é destacada como importante e indispensável, mas em momento algum como fim exclusivo ou superior à "satisfação pessoal".

Os principais termos (maior frequência de aparecimento no conteúdo analisado) relacionados à importância do trabalho artesanal para as mulheres durante as entrevistas foram: "satisfação pessoal"; "concilia com o trabalho doméstico"; "estimula criatividade"; "horário flexível". Estes termos nos permitem compreender os fundamentos da categoria que denominamos de "satisfação pessoal". As Representações Sociais do trabalho artesanal contêm sentidos de um processo fundamentado em dimensões não econômicas. Isso expressa uma diferença básica em relação à categoria anterior analisada.

As mulheres entrevistadas vinculam o trabalho artesanal a fatores que dizem respeito às condições necessárias para manutenção da harmonia entre o trabalho e a pessoa, entre a pessoa e a família, e da pessoa consigo mesma. Trata-se de um processo simbólico de construção do artesanato, no qual lhes são conferidos atributos não econômicos que configuram a construção social dessa atividade. Para além de seu valor de troca, o artesanato é feito pelo seu valor de uso, ${ }^{6}$ pela valorização do processo do qual decorre, que envolve a intimidade da pessoa com o objeto criado: "o trabalho artesanal é uma satisfação. É uma satisfação por saber que as coisas foram feitas por nossas próprias mãos" (mulher entrevistada).

\footnotetext{
${ }^{6}$ O valor de uso é considerado a utilidade de um objeto, que está atrelado as suas qualidades físicas, o valor de troca é a transformação do objeto em mercadoria, calculado através do tempo de trabalho socialmente necessário para definir seu valor, possibilitando sua finalidade de troca. A diferença entre valor de uso e valor de troca é apresentada e discutida por Karl Marx (1989).
} 
Neste sentido, o processo de trabalho é também e, sobretudo, um processo criativo. Permite explorar as habilidades manuais, mas também ativar a criação subjetiva, que é posteriormente objetivada na formação do produto por meio das próprias mãos da artesã. Essa dimensão criativa do trabalho é um dos fatores-chaves explicativas desta categoria, pois o exercício da criação, a objetivação da criatividade, é também um condicionante para a satisfação pessoal. A satisfação pessoal e a criatividade enquanto dimensões não econômicas do trabalho artesanal são, por sua vez, condicionantes da dimensão econômica para as entrevistadas, assim como podemos observar na fala de uma artesã que produz pães caseiros: "o importante é a criatividade na produção dos pães. Quando somos nós que criamos, nós temos até mais carinho na venda. [...] se tem um bom produto, desenvoltura: dá certo! porque o que a gente faz com carinho e com amor... vende bem" (mulher entrevistada). Percebe-se, nessas palavras, a valorização de outros fatores no processo de venda que não apenas o preço dos produtos. O produto é carregado de valores, e seu valor de uso antecede seu valor de troca.

A satisfação pessoal também está atrelada à possibilidade de realização do trabalho na esfera doméstica. A conciliação da produção do artesanato com as atividades diárias da unidade doméstica foi relatada por três mulheres entrevistadas como um fator muito positivo para a continuidade dos trabalhos e um estímulo a outras habilidades que não apenas tarefas domésticas. O trabalho artesanal sendo realizado em casa em alguns casos é importante porque, por exemplo, "dá para cuidar do filho enquanto faz o trabalho" (mulher entrevistada).

Portanto, as Representações Sociais do trabalho nesta categoria formam-se a partir do espaço familiar e para o espaço familiar. Elas são construídas na essência das interações sociais na família, no espaço simbólico da casa. Elas se reportam à esfera familiar como um valor, como o espaço da criatividade e do convívio mútuo entre as responsabilidades diárias e as possibilidades de geração de renda. Por isso se formam para o espaço familiar, para a valorização desse espaço como o espaço da mulher, não enquanto "aprisionamento", mas como espaço social da família. 


\section{Considerações Finais}

Podemos considerar a partir destas reflexões que as Representações Sociais do trabalho artesanal para os associados da Adapac entrevistados variam de acordo com uma distinção de gênero. Entretanto, é importante sinalizar a trajetória dos entrevistados até seu ingresso no trabalho artesanal. As condições de vida, expressas nestas trajetórias, afirmam com veemência a marca social das representações, assim como seu estatuto epistemológico marca a sua função simbólica, e os processos e estados, o seu caráter prático (ARRUDA, 2002).

As Representações Sociais devem ser relacionadas às condições sociais sob as quais emergiram e ao contexto social em que estão imersas. Essa premissa pôde ser operacionalizada empiricamente neste trabalho, o qual possibilitou interpretar que as representações variam de acordo com o objeto representado, com quem o representa e os repertórios socioculturais que os orientam. No caso analisado, o trabalho artesanal surge num contexto em que este tipo de trabalho não é tradição da cultura local, logo está associado a questões de modo vida e alternativa de geração de renda de quem o desenvolve. É importante extrair destas análises que o trabalho artesanal, como processo social, é desempenhado sob inúmeras concepções e entendimentos, que orientam a prática econômica. Mas apesar da variedade de Representações Sociais sobre o trabalho artesanal que marcam os artesãos de uma mesma associação, o trabalho é realizado em cooperação, pois existe a consciência, e esta é quase que consensual, de que o trabalho artesanal associativo e o ponto fixo de venda é uma estratégia importante de manutenção deste segmento e para a reprodução das famílias nele inseridos.

A falta de oportunidade de inserção no mercado formal de trabalho é uma das principais questões apontadas, que justifica a criação da representação da atividade artesanal como saída à geração de renda. A oportunidade de ocupação também é importante fator, principalmente entre as mulheres e homens de idade mais avançada. $\mathrm{O}$ fato é que para ambas as categorias de entrevistos a atividade é uma forma de complementação de renda, apesar de trazer imbuídos outros significados importantes. Existem, assim, vários significados que dão significância a um mesmo objetivo, entremeada por diversas dimensões da vida social (cultural, simbólica, econômico etc.) 
As Representações Sociais do trabalho artesanal para as mulheres se associam a uma condição de satisfação pessoal, a dimensões não econômicas que moldam as valorações sobre o trabalho. Isso qualifica a noção de valor de uso do artesanato em detrimento ao seu valor de troca. Já para os homens, as representações sociais indicam a valorização da dimensão econômica do trabalho artesanal. Isso se explica por uma distinção de gênero, pela diferente interpretação do trabalho a partir de uma divisão sexual, em que a mulher se encarrega dos trabalhos domésticos e o homem dos trabalhos externos. Neste contexto, o trabalho artesanal, representado como um trabalho executado na esfera familiar é concebido, também, como um trabalho doméstico, portanto, um trabalho basicamente feminino. A parte comercial, externa ao ambiente familiar, é atribuição dos homens, seguindo essa divisão sexual do trabalho, configurada por determinadas Representações Sociais.

Quando o trabalho artesanal é representado como trabalho eminentemente doméstico é atribuído o significado de ocupação basicamente feminina. O trabalho "leve" normalmente é executado pelas mulheres e o trabalho "pesado" entre os homens. Por isso mesmo, entre os homens entrevistados, essa é a segunda opção de geração de renda. Esta explicita distinção de gênero, que por vezes traz embutida nas Representações Sociais certos traços machistas e até mesmo preconceituosos no que se refere ao trabalho da mulher, precisa ser contextualizada e relativizada nas análises, assim como buscamos fazer, para que não seja reproduzida. As Representações Sociais, neste sentido, possuem lastros nas trajetórias históricas e nos processos de socialização em que os individuais e grupos vivenciam.

As Representações Sociais são, portanto, catalisadores da ação humana, pois atuam no processo de interação social e na dinâmica familiar. São também condicionantes da reprodução familiar, orientando tacitamente a organização do trabalho, as atribuições individuais e coletivas e os papéis específicos desempenhados por cada membro da família na atividade econômica desenvolvida. A partir deste trabalho evidencia-se que o conceito de Representações Sociais manifesta uma importância indispensável na vida social e expressa ferramenta relevante para compreender as interações sociais e as manifestações do trabalho. 


\section{Referências}

ARRUDA. A. Teorias das representações sociais e teorias de gênero. Cadernos de Pesquisa, São Paulo, v. 7, n. 117, p. 127-147, nov. 2002.

BARDIN, L. Análise de conteúdo. Lisboa: Edições 70, 2009.

DURKHEIM, E. Introdução e conclusão. In: As formas elementares da vida religiosa: o sistema totêmico na Austrália. São Paulo: Abril Cultural, 1978. p. 203-245. (Coleção Os pensadores).

GIL, A. C. Como elaborar projetos de pesquisa. São Paulo: Atlas, 2002.

HOROCHOVSKI, M. T. H. Representações sociais: delineamentos de uma categoria analítica. Em Tese, Florianópolis, v. 2, n. 1, p. 92-106, jan./jun., 2004.

JODELET. D. Representações sociais: um domínio em expansão. In: JODELET, D. (Org.). As Representações sociais. Rio de Janeiro: EDUERJ, 2002. p. 17-44.

LAVILLE, C.; DIONNE, J. A construção do saber. Belo Horizonte: UFMG, 1999.

MARX, K. O capital: crítica da economia política. 13. ed. Rio de Janeiro: Bertrand Brasil, 1989. v. 1.

MOSCOVICI, S. Notes towards a description of social representations. European Journal of Social Psychology, Sussex, v. 18, n. 3, p. 211-250, Jul. 1988.

2003.

. Representações sociais: investigações em psicologia social. Petrópolis: Vozes,

OLIVEIRA, M. S. B. S. Representações sociais e sociedades: a contribuição de Serge Moscovici. Revista Brasileira de Ciências Sociais, São Paulo, v. 19, n. 55, p. 180-186, jun. 2004

TRIVIÑOS, A. Introdução à pesquisa em ciências sociais: a pesquisa qualitativa em educação. São Paulo: Atlas, 1987.

Recebido em: 25/10/2010

Aprovado em: 23/11/2010 